\title{
BMJ Open Qualitative case study investigating PAX-good behaviour game in first nations communities: insight into school personnel's perspectives in implementing a whole school approach to promote youth mental health
}

Yu Qi Wu, ${ }^{1}$ Mariette Chartier, ${ }^{1}$ Gia Ly, ${ }^{1}$ Ari Phanlouvong, ${ }^{1}$ Shelby Thomas, ${ }^{1}$ Jonathon Weenusk, ${ }^{2}$ Nora Murdock, ${ }^{3}$ Garry Munro, ${ }^{2}$ Jitender Sareen ${ }^{4}$

To cite: Wu YQ, Chartier M, Ly G, et al. Qualitative case study investigating PAX-good behaviour game in first nations communities: insight into school personnel's perspectives in implementing a whole school approach to promote youth mental health. BMJ Open 2019;9:e030728. doi:10.1136/ bmjopen-2019-030728

- Prepublication history and additional material for this paper are available online. To view these files, please visit the journal online (http://dx.doi. org/10.1136/bmjopen-2019030728).

Received 29 March 2019 Revised 27 July 2019 Accepted 23 August 2019
D) Check for updates

(c) Author(s) (or their employer(s)) 2019. Re-use permitted under CC BY-NC. No commercial re-use. See rights and permissions. Published by BMJ.

For numbered affiliations see end of article.

Correspondence to Dr Mariette Chartier; Mariette_chartier@cpe. umanitoba.ca

\section{ABSTRACT}

Objectives PAX-Good Behaviour Game (PAX-GBG) is associated with improved mental health among youth. First Nations community members decided on a whole school approach to facilitate PAX-GBG implementation, by offering intervention training to all staff members in their schools. Our objective is to gain a greater understanding of how this approach was viewed by school personnel, in order to improve implementation in remote and northern First Nations communities.

Design We conducted a qualitative case study using semi-structured interviews.

Setting Interviews were conducted in First Nations schools located in northern Manitoba, Canada, in February 2018.

Participants We used purposive sampling in selecting the 23 school staff from First Nations communities.

Intervention PAX-GBG is a mental health promotion intervention that teachers deliver in the classroom alongside normal instructional activities. It was implemented school-wide over 4 months from October 2017 to February 2018.

Outcome measures We inquired about the participants' perception of PAX-GBG and the whole school approach. We applied an iterative coding system, identified recurring ideas and classified the ideas into major categories. Results Implementing the PAX-GBG whole school approach improved students' behaviour and created a positive school environment. Students were learning self-regulation, had quieter voices and demonstrated awareness of the PAX-GBG strategies. All teachers interviewed had used the programme. Support from school administrators and having all school personnel use the programme consistently were facilitators to successful implementation. Challenges included the timing of training, lack of clarity in how to implement and implementing among students in older grades and those with special needs.

Conclusions The whole school approach to implementing PAX-GBG was viewed as an acceptable and feasible way to extend the reach of PAX-GBG in order to promote the

\section{Strengths and limitations of this study}

- Use of qualitative interviews of 23 school personnel in three remote First Nations communities provided rich data to understand their perspectives on PAXGood Behaviour Game enhancement implementation in the context of their communities.

- Collaborating and co-learning with First Nations communities is important in improving mental health promotion sustainably while respecting the cultural and historical context of Indigenous people.

- A limitation of this study is the potential positive bias of the researchers that may have resulted in the school personnel providing more positive feedback on PAX and limiting criticism of the programme.

mental health of First Nations youth. Recommendations included ensuring school leadership support, changes to the training and cultural and literacy adaptations.

\section{INTRODUCTION}

Rates of suicide among Indigenous youth are five to seven times higher than non-Indigenous youth in Canada, and one of the highest suicide rates in the world. ${ }^{1-3}$ One of Canada's Truth and Reconciliation Commission (TRC)'s call to action is to close the health equity gap between Indigenous and non-Indigenous people using health indicators such as suicide rates. ${ }^{4}$ Decades of discrimination, assimilation, oppression and marginalisation have adversely marked countless Indigenous families and eroded the traditional way of life. ${ }^{56}$ However, the damage does not remain in the past, the harmful effects are likely to extend to subsequent generations unless effective measures are taken. ${ }^{1}$ To improve Indigenous well-being, we must take into 
account the contemporary and historical-cultural context of Indigenous communities, and approach health improvement using a collaborative and holistic view that encompasses a balance of spiritual, mental, emotional, physical and social well-being. ${ }^{67}$

A programme that holds promise to closing the health equity gap is the PAX-Good Behaviour Game (PAX-GBG). GBG, developed by Barrish and colleagues, ${ }^{8}$ is a mental health promotion intervention that teachers deliver in the classroom setting alongside the normal instructional activities. PAX-GBG is an enhancement of GBG designed to improve the students' social-emotional competence and behaviour through improved academic achievement, ${ }^{9}$ reduced aggressive and criminal behaviours, ${ }^{10-12}$ decreased tobacco, alcohol and drug use ${ }^{13}$ and decreased use of services for problems with emotions, behaviours or drugs and alcohol. ${ }^{9-14}$ Most importantly, it is one of the few evidence-based approaches that reduce suicide attempts in youth. ${ }^{15}$ The intervention helps strengthen the students' self-regulation and behaviour management skills using strategies that engage the students and teachers to collaborate together in creating a positive learning experience. Currently, PAX-GBG implementation research examines individual and school level factors that affect the programme integration outcomes. ${ }^{16} 17$ Diverse international populations have achieved positive outcomes in implementing PAX-GBG. ${ }^{18}{ }^{19}$ Yet, there is a paucity of research on implementing PAX-GBG in Indigenous communities. Adopting the programme in Indigenous communities requires attention to the unique challenges that First Nations' communities face: high teacher turnover rate, small and mixed grade classrooms and geographical disconnect between schools. Understanding the implementation of programme that promote mental health and prevent suicides is crucial in ensuring programme effectiveness.

As described above, evidence-based community interventions with promising suicide-reduction outcomes are available. ${ }^{1520}$ However, without proper implementation that considers the real-world context of Indigenous communities, the interventions may fail to yield positive outcomes. ${ }^{21}{ }^{22}$ Implementation science refers to the process of integrating evidence-based interventions within a specific setting in order to benefit population health. ${ }^{22}{ }^{23}$ Implementation strategies are often used, which are the set of systematic processes, activities, resources used to adapt interventions into practice. ${ }^{24}$ There are several important aspects of implementation: fidelity (adherence to original intervention), dosage (frequency and duration of delivering the intervention), quality (degree of excellence of the components of the programme conducted), participant responsiveness (degree the programme stimulates interest in participants), programme differentiation (degree the programme is distinguished from others), monitoring of control/comparison conditions, programme reach (rate of participant involvement) and adaption (programme modification and reinvention)..$^{2125}$
We found a unique opportunity to address the programme implementation research gap in the province of Manitoba, Canada. In 2011, Manitoba conducted the first province wide cluster randomised control trial (RCT) for all interested grade I classrooms to adopt PAX-GBGinto their curriculum in effort to decrease suicide rate through early mental health promotion. Academic researchers have partnered with First Nations communities, the government of Manitoba and PAX-GBG developers to collaboratively explore PAX-GBG's implementation and determine if enhancements were required. First Nations community members recommended two enhancements of PAX-GBG: the whole school approach and the Dream Makers approach. The whole school approach involves training all school staff in using PAX-GBG in their classrooms and all school activities, thereby better aligning it with the socio-cultural context of the remote communities. The Dream Makers approach is still being evaluated and will be reported in a separate paper. The PAX-GBG trainers travelled to the northern communities and provided a 2 day training to teachers from Kindergarten to Grade 8. In two of the three schools, the trainers also demonstrated how PAX-GBG was actually used in the community's classroom.

The objective of this study is to examine the perspective of school personnel on the implementation of the PAX-GBG whole school approach. Implementation research is essential in understanding how evidencebased mental health promotion programme are being used within real-world remote and northern contexts. The insights gained can be used to support the application of PAX-GBG into practice and improve the mental well-being of youth.

\section{METHODS}

This qualitative study used a case study design, the case being the PAX-GBG intervention. A case study is an appropriate design for both in-depth exploration of a programme such as PAX-GBG, and of evaluation the implementation of an intervention. We conducted in-depth one-on-one interviews of school staff involved in implementing PAX-GBG in First Nations schools located in Manitoba, Canada. Specifically, participants were asked about their overall impressions of the whole school approach, the benefits and challenges of implementation, the PAX-GBG training and changes they would recommend. Content analysis of the extensive interviews helped gain a holistic perspective on the reception and real-world practices of PAX-GBG whole school approach. The standards for reporting qualitative research reporting guidelines were used. ${ }^{26}$ This study was approved by the University of Manitoba's Health Research Ethics Board, Winnipeg, Manitoba, and written informed consent was obtained by all participants.

\section{Study setting and sample}

In Canada, the term 'Indigenous' includes First Nations, Métis and Inuit people. This study focuses on First 
Nations peoples comprising $10.5 \%$ of Manitoba population, which is the highest proportion among the Canadian provinces. On the First Nations communities' recommendation, three schools implemented PAX-GBG in Kindergarten to Grade 8 classrooms in northern and remote communities in the province of Manitoba, Canada. The school personnel were trained in how to use the PAX-GBG approach in their schools and were expected to begin implementing school wide after the training. The principal of each school invited school personnel to share their experience voluntarily with the research team. The interviewees included three principals, 17 teachers, one educational assistant (EA) and two resource teachers who were employed in one of the three schools. The majority (14) of the participants interviewed taught the early years students (Nursery to Grade 3 ), and five worked in the middle years (Grade 4 to 8 ), only one in high school (Grade 9 to 12) and the three principals oversaw all grade levels. Of those interviewed, there were 15 school staff members who attended the 2-day PAX-GBG whole school training conducted in October 2017 in their own schools, six staff members attended the regular PAX-GBG training in a major centre, two of which also attended the PAX-GBG whole school training. Only two staff members did not attend any training in PAX-GBG.

Four female researchers made up the research team: the principal investigator has a $\mathrm{PhD}$, the research associate has a MSc with experience in qualitative research, the graduate student has training in qualitative interviews and the medical student was new to interviewing. The students were Indigenous and the others were not. Other than discussions with the school leadership about the project, the interviewers had no prior contact with the participants. Although the research team has no vested interest in PAX, they began the study with a positive attitude towards the programme based on previous research results and evidence in literature.

\section{Data collection}

We conducted 23 in-depth, semi-structured, open-ended one-on-one interviews in February 2018 at the three schools. The interviews were evenly distributed across the three schools and lasted between $15 \mathrm{~min}$ to $45 \mathrm{~min}$. During data collection, the participant and one or two researchers were present. Each interviewer explained the purpose of the interview and had a structured interview guide with prompting questions for consistency (see online supplementary appendix A). The interviews were audio taped and transcribed verbatim. The research team unanimously agreed that this study had reached data saturation because no new information emerged nearing the end of each interview day. Field notes were made after the interviews and no repeat interviews were conducted. We did not return the transcripts to the participants; however, we shared the themes and subthemes with some of the participants for feedback to ensure accuracy.

\section{Analytical strategy}

The research team (three members) conducted the lineby-line analysis of the individual transcripts. Initially, the data was grouped according to the interview questions. Then, all the results were compiled and categorised into major categories. Six main categories and 20 subcategories emerged from our analysis of the interviews. Techniques used to ensure validity included obtaining the perspectives of classroom teachers, resource teachers and principals, reaching consensus on the categories by two researchers and confirming them by a third research and member checking with a subsample of the participants.

\section{Patient and public involvement}

Through a series of community meetings, First Nations community members were involved in developing the research proposal, including the research objectives and design. These members were either band leadership, service providers, school personnel or simply interested members of the community. Some members were part of monthly team meetings overseeing the study and some sat on the PAX Adaptation committee that reviewed the results and provided context to ensure the findings were interpreted accurately. They recommended the expansion of PAX-GBG in their communities, identifying areas of interest regarding implementation and encouraging school staff in participating. However, they were not involved in conducting or analysing this study. The research team has shared and discussed these results with a working committee at an annual meeting, which included three members of eight First Nations communities, and at a national conference. All participating sites and partner communities have received a newsletter and a two-page summary of the study results.

\section{RESULTS}

The school personnel shared their thoughts and experiences with the research team regarding (1) overall impression of PAX-GBG, (2) impact of PAX-GBG, (3) implementation of the PAX-GBG whole school approach, (4) facilitators to implementation, (5) challenges to implementation and (6) PAX-GBG training, as shown in table 1.

\section{Overall impression of PAX-GBG Improved student behaviour}

Participants were generally receptive towards implementing PAX-GBG in their classrooms, finding that it created a positive school environment and improved students' behaviour. School personnel noted that PAX-GBG was effective in improving the student's attitude, the loudness of their voice and their self-control as well as more order in the hallways. One teacher commented that 'the kids are friendlier and ... they don't tease as much, and they follow the rules better ... it's just more peaceful'. (S1-I5)

\section{Positive school environment}

In terms of a positive school environment, several commented on how students were having fun in class and 


\begin{tabular}{|c|c|c|c|}
\hline \multicolumn{2}{|c|}{ Major themes } & \multicolumn{2}{|c|}{ Subthemes } \\
\hline \multirow[t]{2}{*}{1} & \multirow{2}{*}{$\begin{array}{l}\text { Overall Impression } \\
\text { of PAX-GBG }\end{array}$} & 1 & Improved student behaviour \\
\hline & & 2 & Positive school environment \\
\hline \multirow[t]{3}{*}{2} & \multirow[t]{3}{*}{ Impact of PAX } & 3 & Students learning self-regulation \\
\hline & & 4 & Quieter students \\
\hline & & 5 & Student's PAX-GBG awareness \\
\hline \multirow[t]{6}{*}{3} & \multirow{6}{*}{$\begin{array}{l}\text { PAX-GBG } \\
\text { implementation }\end{array}$} & 6 & PAX harmonica and PAX quiet \\
\hline & & 7 & PAX vision exercise \\
\hline & & 8 & PAX-GBG and Granny's Wacky Prize \\
\hline & & 9 & PAX sticks \\
\hline & & 10 & Tootle notes \\
\hline & & 11 & PAX posters \& PAX hands and feet \\
\hline \multirow[t]{2}{*}{4} & \multirow{2}{*}{$\begin{array}{l}\text { Facilitators of PAX } \\
\text { implementation }\end{array}$} & 12 & Administrative support \\
\hline & & 13 & Consistency among school personnel \\
\hline \multirow[t]{4}{*}{5} & \multirow[t]{4}{*}{$\begin{array}{l}\text { Challenges of PAX } \\
\text { implementation }\end{array}$} & 14 & $\begin{array}{l}\text { PAX strategies do not appear } \\
\text { compatible for all ages. }\end{array}$ \\
\hline & & 15 & Training too late in the school year \\
\hline & & 16 & Lack of clarity on how to implement \\
\hline & & 17 & $\begin{array}{l}\text { More instructions needed to } \\
\text { implement PAX with special needs } \\
\text { children }\end{array}$ \\
\hline \multirow[t]{3}{*}{6} & \multirow[t]{3}{*}{ PAX-GBG training } & 18 & $\begin{array}{l}\text { Trainings held in school gym makes } \\
\text { it hard for participants to hear the } \\
\text { trainers properly }\end{array}$ \\
\hline & & 19 & $\begin{array}{l}\text { Middle years teachers felt some of } \\
\text { the training were meant for early } \\
\text { years classrooms }\end{array}$ \\
\hline & & 20 & $\begin{array}{l}\text { Pace is too fast when there was only } \\
\text { one whole school training }\end{array}$ \\
\hline
\end{tabular}

PAX-GBG, PAX-Good Behaviour Game.

enjoying themselves in school. Some of their comments also suggest that PAX-GBG has provided teachers with new skills for improving the classroom environment. One teacher noted, 'this one student said, I can't believe like we're having fun in school, 'cause he's so used to a strict routine of just sitting there doing work, doing work, and not playing or doing anything, making things fun' (S1-I5). Others commented on its positive influence:

Just that's it's more positive and kind of get the kids to think about themselves and what you're doing or what your group is doing and instead of more punishment, like put your heads down or turn the lights off or all these different things. (S2-I6)

School staff can be influenced by how other educational staff view the programme thereby making them less receptive to PAX-GBG. One of the teachers spoke about hearing negative comments about PAX-GBG from staff in a different school before she was trained. However, her impressions changed after she attended the training herself.

They were talking about PAX, how they were trying to promote it into the schools and ... like the math specialist, the ELA specialist, all those specialist people wanted, they didn't agree with the programme because they were saying that you're rewarding kids and they don't believe in rewarding kids for good and bad behaviour. (S2-I4)

Then when I went into the training I got a good idea of it and I was like, no, its not negative, its good. (S2-I4)

\section{Impact of PAX}

Participants also discussed the changes they observed within their own classrooms and throughout the school as shown in table 2. Most noted that the observed changes were positive. The most common observations mentioned were that students were learning self-regulation, control over their voices and increased awareness of PAX strategies. However, some participants mentioned that they had observed only few changes. As one person said, 'well there's a few I guess, it is improving a little bit, but I don't think everybody's following through with it' (S3-I6). They found that some teachers are still raising their voices to get the attention of the students, rather than using the PAX-GBG strategies. The school bus was mentioned as a place where misbehaviour was noticed.

Table 2 Observed changes in school after the implementation of PAX whole school approach

\begin{tabular}{|c|c|}
\hline Impacts of PAX & Key informant statements \\
\hline $\begin{array}{l}\text { Students are learning } \\
\text { self-regulation }\end{array}$ & $\begin{array}{l}\text { Well like I said their attitudes, their voices, they have self-control, they practice self-control. They no } \\
\text { longer shout answers, they know to raise their hand quietly and respectfully. (S1-I2) }\end{array}$ \\
\hline $\begin{array}{l}\text { Students are } \\
\text { demonstrating } \\
\text { knowledge about PAX- } \\
\text { GBG }\end{array}$ & $\begin{array}{l}\text { I noticed the harmonica one, the harmonica signal, as soon as you blow on that harmonica they know, } \\
\text { like in assembly, they quiet down and they get on track. So the harmonica really has influenced a lot - } \\
\text { the, up to grade } 6 \text { - I guess, because they know now that harmonica signal. (S3-I3) the last (assembly) } \\
\text { I was at it was not too bad, so possibly that could have been a result of the PAX, so from about 3, } \\
4 \text { months ago to the last month or so there's definitely been an improvement. (S2-I2) }\end{array}$ \\
\hline
\end{tabular}

PAX-GBG, PAX-Good Behaviour Game. 


\section{PAX-GBG is being implemented}

Almost all study participants indicated use of PAX-GBG; however, the frequency of PAX use varied. Unfamiliarity with PAX-GBG was a reason that some participants were only beginning the implementation of PAX-GBG:

The initial training was good as is and it's just a matter of getting out there and trying a little by little... you don't just go in the next morning and...I'm using PAX, that's it. It doesn't work like that for anything. (S3-I2)

They're a lot more comfortable, like there were people who had no clue what PAX was. And I think they're more comfortable and I'm sure, like when you get a chance to question them you'll find that it's mainly positive. The only holdback might be because I've had previous training I was more aware of it, so somebody coming in totally new at it and having a whole classroom to do it with might make a difference you know. But it was very positive, they were very positive I think. (S3-I2)

All participants with the exception of one have used a PAX-GBG strategy since they were trained in October 2017. The PAX-GBG strategies are described in online supplementary appendix B. However, it is clear that the PAX-GBG strategies are used to varying degrees. Of the 17 classroom teachers, few were using the full range of strategies. PAX harmonica was most often mentioned among the seven PAX-GBG strategies, followed by the PAX Sticks, PAX Vision Exercise and PAX hands and feet. While many school staff have used several strategies, in some cases they were not used as intended. The benefits and challenges with some of the strategies are explained below. Table 3 shows staff's perspectives on the PAX strategies.

\section{PAX vision exercise}

Nearly half of the participants mentioned the vision exercise and spoke positively when describing their experiences. A few mentioned that they had not facilitated the exercise. One teacher noted it was challenging to motivate her students to participate in this exercise.

\section{PAX-GBG, Granny's Wacky Prizes and the term 'spleems'}

Some teachers spoke about how well their students responded to the PAX-GBG and Granny's Wacky Prizes. A few teachers spoke about counting spleems (disruptive behaviour), however, many had not started counting them in their classrooms Many of the teachers who played the game made some modifications to adapt it to their classroom and culture. Of those who did not play the game, unfamiliarity, lack of class time and the dislike of the word 'spleem' restricted the game from being played.

\section{PAX harmonica and PAX quiet}

Most of the participants used the harmonica; however, a few used it less often because of the small class size. While describing their experiences with the harmonica, several teachers spoke about the use of the peace sign and how it is useful in getting the student's attention. Interestingly, one person spoke about how the harmonica can help with student safety.

\section{PAX sticks}

Several teachers spoke about using the PAX sticks and how well their students responded to the strategy. The teachers felt the strategy helped students, particularly shy students, gain confidence to interact with others. One use of the PAX sticks is to randomise the likelihood a student is called to answer a question, other teachers have used the PAX sticks to help them choose a helper or leader.

\section{Tootle notes}

Tootle notes appeared to be used in varying degrees. A few teachers had their classes write notes on a regular basis while others used them once a week or during special occasions. A teacher also used tootle notes to help her with supporting students. However, some teachers are confronted with some challenges in implementing the strategy. Finding the time to write the Tootles notes for some teachers appeared to be a large undertaking. They felt that using the Tootles would add another responsibility to their already full schedules.

\section{PAX posters and PAX hands and feet}

PAX posters were mentioned to help students' learn about appropriate noise levels. Only a few teachers spoke about their experiences with PAX Hands and Feet. These teachers described their use of this strategy positively.

\section{Facilitators of PAX implementation Administrative support}

School personnel discussed important aspects on effectively implementing PAX-GBG. Many of the participants mentioned that it was crucial to have the support of the school administration, especially the principal's support. As one teacher described, 'the teachers had that support from the staff and the principal brought it in, actually the PAX training for everyone and encouraged everyone to attend it and just made it real fun and informative workshop. And then she encouraged them to use, and we helped and they offered help and they still do, they were still about helping people get started and maintained in their programming. So with that support, that's an important part too.' (S3-I2)

\section{Consistency among school personnel}

Some staff members mentioned that it was easier to implement PAX-GBG because all staff have been trained and the message to students was consistent. Other staff members supported the PAX-GBG whole school approach because it made implementing the programme easier for the teachers and provided consistency for the students. As one staff members noted, 'Because it was everybody together the initial training and then everybody was using it, you know it's consistent so I noticed it.' This consistency was frequently mentioned as crucial to successful programme implementation, 'It works, but you have to be consistent every day. 
Table 3 PAX strategies implemented in the school

Strategy Description Key informant statements

PAX vision exercise Teachers and students - to increase selfregulation create a large chart that is posted on the wall of what they would like and would not like to see, hear, do and We did it in the beginning and we went through the beginning steps of it and feel in an optimal classroom talked about it in the class. They're really standoffish, nobody wants to talk. Because it's hard to get them to speak in front of the classroom, express their ideas, they don't want to be made fun of. (S1-15)

\section{PAX-GBG}

and Granny's

Wacky Prize - to motivate student participation and increase prosocial behaviours

I actually put it up on my wall and we went through all the 'do more' and then what our classroom wants 'less of' ... it's their input on there so I put it up on the wall and it's on our wall right now. And I refer back to it all the time. up on the wall and it's on our wall right now. And Ir

(the students) really liked it... I changed (the game's name)'cause it was

Teachers set a timer and challenge students to avoid behaviours agreed on in the PAX vision exercise. If students succeed, an intrinsic reward is given. called Granny's Wacky Games, so I just changed it to Kookum, that they were Kookum's Games. I wanted to make some of the games a little more age appropriate because some of them are really a little hard for us. Just to incorporate some of our own culture into it, getting the kids, 'cause we've been trying to make our kids more fluent in Cree. (S2-17)

I tend to forget to do the games 'cause we're so busy with reading and we don't have time for the games. So I think that's the only thing that I'm not doing - is the game part. (S2-14)

$\begin{array}{ll}\begin{array}{l}\text { Harmonica and PAX } \\ \text { quiet - to increase } \\ \text { productivity in the } \\ \text { classroom }\end{array} & \begin{array}{l}\text { verbal transition cue (eg, } \\ \text { harmonica) to signal a shift } \\ \text { in attention or task in a } \\ \text { patterned way }\end{array} \\ \begin{array}{ll}\text { PAX sticks - to } & \text { Random selection of } \\ \text { encourage students } & \text { students for participation } \\ \text { to maintain focused } \\ \text { in class }\end{array}\end{array}$

Tootle notes - to promote prosocial behaviours
Positive notes written from one student to another
When I want their attention I use the harmonica and all of them make sure they show me their peace sign and they're looking at me and they're quiet and yes all of them just stop what they're doing and look. (S1-15)

You have to do it consistently, if you don't do it then they'll forget all about it and that's one thing I do, is do it consistently. (S2-19)

I love that one too because all their names are on there and they all have a chance to do whatever, be the helper of the day or whatever and they respond well to that. The shy ones are kind of coming out of their little shells. So yeah, it kind of makes them more confident. (S1-15)

I had a parent come up to me and said, 'D' doesn't want to be in this class, he feels like he has no friends, he feels that the boys don't ever want to interact with him. So then I took ' $D$ ' to the Tootles board and I showed him, one of the two other boys wrote a Tootles to him and it just brightened up his day, I read it to him and one of the Tootles that was addressed toward him was, 'thank you for being such a great friend, you helped me with math', and you could see it in him that it helped him a bit. Then he started interacting more with the other student and thanking ' $R$ ' and just helping ' $R$ ' more, so in that way the Tootles was pretty good. (S2-11)

I feel like the Tootles for me right now are just more, more work for me among the 500 other things that I have to be doing in a day. (S2-17)

\begin{abstract}
The posters in the classroom, yeah, I would hang them up and we'd refer back to it. It was PAX reminders, so its not only me that's reminding the kids, it's all the different things in the classroom. (S2-11) ways to hold one's hands and feet when walking in the halls, making transitions I like that too because they know to keep their hands to themselves and then or other classroom activities I have my daily rules, you know number one, keep your hands and feet to yourself number two, but my number three rule is walk quietly with your PAX (hands) and your PAX feet. (S3-I3)

Demonstrates acceptable or other classoom activities 11
\end{abstract}

\section{PAX posters \& \\ PAX hands and feet to promote self-regulation and to increase productivity in the classroom}

You can't just say, oh we're going to do PAX and then not follow through. And you have to explain to the kids how the programme works, like when you blow the mouth organ for quiet and the voice the PAX voice, all the charts are up and they know, and even on the door PAX hands are on there, the posters are all up. And they all know that, so you have to teach the kids how it works before you can do it and be consistent every day and follow through with it, because if you don't then it will just, it will just fall through, it won't work for you in the classroom management, so it's (Whole School Approach) very good for that' (S3-I6).

\section{Challenges of PAX implementation}

As shown in table 4, participants raised four major challenges from their experience in implementing PAX-GBG. First, many school staff view the PAX programme as being designed for younger children, and not age appropriate for the older grades, indicating the need for modifying the materials and the training for teachers in older grades. It should be noted that the programme has been previously used in older grades in the USA. Second, starting the training in October made it difficult for 
Table 4 School personnel's challenges in implementing PAX-GBG whole school approach

Challenge Key informant statements

PAX strategies do not My grade 8 students were like, that's for babies, like it's for younger kids and they don't think, they appear compatible for all don't feel like it's suited for them... And the language in there I guess they feel too young and ages the games... they think are too young, 'cause one of them was like hop up and down for 10s or something, spell out your name clapping different, like those games were more for the younger kids too. (S2-16)

Training too late in the Well its planning, that's all it takes is planning, you just got to do it. And like, like I said if it was given school year prior to the new starting I probably would have tried to plan to use it, so. I would use it, I would because my grade $2 s$ are usually from grade 1, from the grade 1 teachers. (...)I don't think it's difficult, its just how you manage your class I guess. (...)When you're going to have time to fit it in because it does take time to do the brainstorming and whatever. (S3-I1)

Lack of clarity on how to
implement

Adaptations needed to implement PAX with special needs children
I was quite impressed with it, but I'm having a hard time implementing it. There's just too many little different things you got to implement in order for it... they say...to work properly. (S2-I5)

For instance, one student I had in the classroom was the type of student where he did not interact with his peers. (...)So it was kind of hard to do those activities, he would be like, don't look at me, don't touch me. (...)He would interact with PAX but it was only one on one. But if I were to do a group activity with him and other students, no wasn't happening. (S2-I1)

PAX-GBG, PAX-Good Behaviour Game.

teachers to revise their curriculum schedules to include the programme. Third, some teachers voiced their lack of clarity on how to actually begin implementing PAX-GBG. Lastly, engaging special needs children into participating in the programme was regarded as difficult to do.

\section{PAX-GBG training}

Participants shared their thoughts on the PAX-GBG training, which includes the lecture approach, trainer classroom visits and training EAs. Furthermore, participants gave feedback on areas of improvement, which can help inform future PAX-GBG training sessions.

First, the trainees appreciated the lecturing approach used in the PAX-GBG training because the trainers often integrated their personal experiences to enhance the participants' learning. The real-world examples of working with children in First Nations communities helped the participants connect with the trainers and believe that implementing PAX in their schools is feasible. Training with colleagues made the training more enjoyable and fruitful because it was easier to interact with one another and share ideas. A teacher who attended both the regular training and whole school training felt that attending training with Winnipeg School Division teachers made her less at ease to interact with the other trainees.

Second, the participants thought the trainers' visit to the teachers' classrooms were very helpful because the trainers could observe their classroom dynamics and settings.

He like visited every class and he had really helpful tips and then he was saying like you know you don't have to go too fast, just start with what you're doing is good, just start with your harmonica and starting to talk about SPLEEMS and stuff like that. Which was good, so that was really nice, because I was thinking, oh no I'm not doing any of the games yet or any of the groups and then counting SPLEEMS, I didn't have a base count or anything like that. So he was like, don't rush into it, that's part of, that it's so flexible that you can just go at your own pace. (S2-I7)

Thirdly, a few teachers in one Swampy Cree Tribal Council (SCTC) school, which had the opportunity to train EAs, felt that training EAs helped make the PAX message consistent to all students.

I really liked that the EA's ... (attended) the whole (PAX) session and they felt good about that too 'cause they, sometimes in the training we forget that and they do a lot of work, you know one on one and behavioural for sure, and classroom management and everything, they really need those skills because there's a number of children they work with. (S3-I2)

Lastly, participants shared some challenges of the training and offered some possible solutions. As shown in table 5, areas of improvement included the setting, approach, frequency of the PAX training sessions and all staff training. Although the whole school training held at the school gym accommodated all trainees, participants felt that it was hard to hear in the large space.

\section{DISCUSSION}

The Truth and Reconciliation Commission (2016) has prioritised closing the health equity gap between Indigenous and non-Indigenous people, including on the measure of youth suicide. ${ }^{4}$ However, translating evidencebased mental health promotion interventions into practice requires careful attention to the historical and cultural context of First Nations communities. A key reason for this is the unique history and challenges that the communities face. While the main focus was Manitoba's Swampy 
Table 5 School personnel's views on training challenges and recommendation on improving future PAX training

\begin{tabular}{|c|c|c|}
\hline Challenge & Possible improvement/change & Key informant statement \\
\hline $\begin{array}{l}\text { Trainings held in school } \\
\text { gym makes it hard for } \\
\text { participants to hear the } \\
\text { trainers properly }\end{array}$ & - Trainings can be held in classrooms & $\begin{array}{l}\text { Maybe a smaller environment 'cause we had it in the } \\
\text { gym hey, 'cause it was big. And it's better if you had it } \\
\text { in a big classroom or something. (S1-15) }\end{array}$ \\
\hline $\begin{array}{l}\text { Middle years teachers } \\
\text { felt some of the training } \\
\text { were meant for early } \\
\text { years classrooms }\end{array}$ & $\begin{array}{l}\text { Separate, tailored training for teachers of } \\
\text { early and middle years teachers }\end{array}$ & $\begin{array}{l}\text { I think that it would be good if they had two separate } \\
\text { trainings, one for the early years and one for the middle } \\
\text { years. Just because I found that the training that } \\
\text { they had here, it was more directed towards the, the } \\
\text { younger grades. (S1-16) }\end{array}$ \\
\hline $\begin{array}{l}\text { Pace is too fast when } \\
\text { there was only one } \\
\text { whole school training }\end{array}$ & $\begin{array}{l}\text { Slow down the pace, and break down } \\
\text { the training to several sessions } \\
\text { Provide webinars to allow staff to learn } \\
\text { on their own time } \\
\text { Opportunity to observe seasoned } \\
\text { teachers in their classrooms }\end{array}$ & $\begin{array}{l}\text { I would probably need more training. That one training } \\
\text { just wasn't sufficient. So that might help and I think } \\
\text { l'd really want to see a good PAX class. Just go and } \\
\text { observe a PAX class. (S2-I5) }\end{array}$ \\
\hline
\end{tabular}

Cree Tribal Council communities, these study results have potential relevance for other Indigenous communities implementing mental health promotion interventions.

While previous studies have looked into teacher factors that influence PAX-GBG implementation outcomes and the effect of implementing the intervention on teachers, ${ }^{161727}$ this study is the first to examine the perspective of school personnel in implementing PAX-GBG whole school approach enhancement. Consistent with previous research we found that programme implementation varied among providers. ${ }^{16} 21$ Based on the interview results, it appears that the level of PAX-GBG implementation (ie, the duration and frequency of using PAX-GBG strategies) is heavily dependent on the teacher's motivation, confidence and familiarity in using the PAX-GBG strategies. There was a high degree of participant responsiveness as key informants and their students were receptive of the PAX-GBG whole school approach. The teachers were also receptive of PAX-GBG enhancement implementation because they observed improvement in student behaviour and school environment.

The majority of school personnel voiced that administrative support was essential in implementing PAX, especially the principal's support. The principals' leadership role is instrumental in prioritising the implementation of PAX in the school, as reflected in allocating resources and training. ${ }^{28}$ A previous study has found that teachers' programme implementation level increases correspondingly when principals are made aware of their positive influence on programme implementation and are explicitly requested to encourage and monitor teachers. ${ }^{29}$ Additionally, principals' willingness may serve in validating the initial acceptance of the intervention within the community and encourage teachers to adopt the programme.

Wehby has found that teacher burnout impedes intervention fidelity - a similar concern raised by the First Nations school staff. ${ }^{30}$ This impediment can be minimised with better teacher-trainer alliance. ${ }^{30}$ In terms of training improvements, the school staff recommended more training opportunities that start before the school staffs begin adhering to their planned curriculum. As Becker suggested, two-phased coaching model is more appropriate for teachers with a variety of skill levels. ${ }^{31}$ In the two-phased coaching model, the initial phase (universal coaching phase) provides all learners the same coaching regardless of their skill level. In the second phase (tailored coaching phase), coaching is aimed at meeting the learners' needs and working with the learners' strengths. As the PAX enhancement expanded training for all school staff, the training needs to both (1) deliver a consistent message to everyone and (2) modify the training according to the specific needs of teachers of different grade levels. The universal coaching phase and tailored phase of the two-phased training model would address both concerns respectively.

In understanding the school staff's perspective in implementing PAX-GBG whole school approach, we have gathered five major recommendations to help improve and ensure that PAX-GBG whole school training enhancement is successful. (1) Administrative support: The principal and administration of First Nations schools play a significant role in supporting the teachers as they show confidence in adopting the school-based health promotion programme, which influences the receptivity of school staff in implementing and enhancing the intervention. (2) Inclusive training: Expanding PAX-GBG training to all school staff seems to align with the communal value of First Nations communities and their holistic approach to health and well-being. Including EAs in future trainings will better ensure a consistent PAX implementation for special needs children and delivering a consistent message throughout the school. (3) Two-phased training: Two-phased training with hands-on workshops is recommended in accommodating the specific needs and responsibilities of different school staff. Starting the training early is important in helping the school staff integrate the intervention into their everyday practice. Frequent trainings rather than longer trainings are preferred. Further, 
a feedback mechanism is recommended in assuring school staff throughout the implementation process. To ensure intervention sustainability, regular feedback will aid in developing improvements. As many of the First Nations communities are remote, it would be pragmatic for teachers who use PAX less confidently to shadow those whom are more familiar with the intervention; co-learning may help encourage continuous learning when the trainers are not available. (4) Cultural adaptation: Cultural modifications are needed to increase the acceptability and use of more PAX games. Specifically, the names of the PAX strategies should be changed to fit the cultural context. (5) Literacy level adaptation: Specifically for Tootle notes, other means to share kind peer feedbacks are needed to overcome the literacy challenge. We propose using verbal and visual substitutes in integrating Tootle notes in lower literacy classrooms.

According to recent evaluations, PAX-GBG may build resilience in high-risk First Nations youth. ${ }^{32}$ However, special attention must be paid to delivering the resources appropriately in order to offset the cumulative effect of poverty, loss of culture and intergenerational trauma, which undermines childrens' mental, emotional and social well-being. ${ }^{20}{ }^{21} \mathrm{~A}$ failure to deliver high quality programme implementation will more likely result in diminished anticipated outcomes. Therefore, this study has taken an important step in providing a holistic foundation of knowledge to help develop effective methods of PAX-GBG implementation enhancements that eases the transition of adopting a validated intervention into realworld practice.

\section{Strengths and limitations}

A key strength of this study is the contribution it makes to a deeper awareness and understanding of the school staffs' perspective on PAX-GBG enhancement implementation in the context of First Nations communities. Collaborating and co-learning with First Nations communities is important in improving mental health promotion sustainably while respecting the cultural and historical context of Indigenous people. Considering the holistic approach of health in Indigenous communities, it is imperative to understand the school staff's perspective of PAX-GBG implementation enhancement. Studies have indicated that adaption (modification or reinvention of interventions that does not alter the core principles of the programme) is an important aspect of implementation. ${ }^{21}$ Although programme adaption may be viewed as a failure to achieve fidelity (adherence to the original intervention), we propose that programme modifications are conducive in achieving higher implementation dosage and maintain programme sustainability. When the 'fit' of an intervention aligns with the school staff's values and beliefs, there is a higher level of implementation. ${ }^{162}$ As proposed by Durlak, focusing on cultural factors in implementation is fundamental to suit the needs and values of specific ethnic populations. ${ }^{21}$ Our study has considered the unique cultural and historical context of First Nations communities.

A limitation of this study may be the potential positive bias of the researchers. This bias may have resulted in the school personnel providing more positive feedback on PAX and limiting criticism of the programme. Another potential limitation of this study is in the reliance on school staff's recall on reporting their impression and experience in implementing PAX-GBG enhancement. Obtaining the points of view of not only classroom teachers, but also principals and resource teachers helped to mitigate this limitation.

\section{CONCLUSION AND FUTURE DIRECTIONS}

The whole school approach to implementing PAX-GBG was viewed as an acceptable and feasible way to extend the reach of PAX-GBG in order to promote the mental health of youth in northern and remote First Nations communities. It also has identified the real-world challenges that school staff face in incorporating PAX-GBG into their practice within rural and remote First Nations communities. This valuable information has provided a basis on which future research and improvement strategies can be identified and developed. Some recommendations to strengthen the approach include ensuring that the school leadership understand PAX-GBG and support their staff, inclusive training of all school personnel, use of two phased training and making cultural and literacy adaptation to the programme. More research is needed to evaluate the effectiveness of these additional supports and adaptations. Also, while previous research found GBG to be effective at improving mental health and academic outcomes in youth in the USA, whether it is beneficial specifically for First Nations youth has yet to be shown. Ensuring culturally and contextually appropriate PAX-GBG implementation will improve the likelihood that First Nations youth will benefit from this evidencebased programme and improve their life-long mental well-being.

\section{Author affiliations}

${ }^{1}$ Department of Community Health Sciences, University of Manitoba, Winnipeg, Manitoba, Canada

${ }^{2}$ Cree Nation Tribal Health Centre Inc, The Pas, Manitoba, Canada

${ }^{3}$ Department of Instructional Services, Manitoba First Nations Education Resource Centre, Winnipeg, Manitoba, Canada

${ }^{4}$ Departments of Psychiatry, Psychology and Community Health Sciences, University of Manitoba, Winnipeg, Manitoba, Canada

Acknowledgements The authors would like to recognise the contribution of the Swampy Cree Tribal Council community members in the conception of this study. The authors met with them over three annual meetings and informally when needed throughout the study. Their guidance has been pivotal in shaping the study protocol. We also recognise the continued support and guidance of the staff at the Cree Nation Tribal Health Centre. The authors acknowledge the generosity and openness of the government partners at Healthy Child Manitoba who fund PAX-Good Behaviour Game (PAX-GBG) in the province of Manitoba and are committed to working with the communities to understand the implementation and evaluation of this intervention. The authors are grateful for the guidance, time, effort and funding that the Manitoba First Nations Education Resource Centre and 
the First Nations and Inuit Health Branch has provided. Finally, the authors extend our gratitude to the PAXIS Institute for their generosity, creativity and enthusiasm in adapting and enhancing PAX for the benefit of Indigenous people.

Contributors YQW had the responsibility of writing the manuscript and contributed to the analyses and interpretation of the data. All authors have reviewed and approved the manuscript. MC and GL contributed to all aspects of study. AP contributed to analyses and interpretation of the data. ST and JW contributed to the design, acquisition and interpretation of the data. NM, GM and JS contributed to the conception, design and interpretation of the data.

Funding Preparation of this article was supported by a 3-year Canadian Institutes of Health Research (CIHR) Team Grant, grant number P12-144646: Pathways to Health Equity for Aboriginal People - Implementation Research Team Grants Component 1 - Suicide Prevention (Chartier, Sareen \& Munro).

Competing interests None declared.

Patient consent for publication Obtained.

Ethics approval This study was approved by the University of Manitoba's Health Research Ethics Board, Winnipeg, Manitoba. ID\# HS19857 (H2016:248).

Provenance and peer review Not commissioned; externally peer reviewed.

Data availability statement № additional data are available.

Open access This is an open access article distributed in accordance with the Creative Commons Attribution Non Commercial (CC BY-NC 4.0) license, which permits others to distribute, remix, adapt, build upon this work non-commercially, and license their derivative works on different terms, provided the original work is properly cited, appropriate credit is given, any changes made indicated, and the use is non-commercial. See: http://creativecommons.org/licenses/by-nc/4.0/.

\section{REFERENCES}

1. Kirmayer LJ, Brass GM, Holton T, et al. Suicide among Aboriginal people in Canada, 2007. Available: http://tps.sagepub.com/content/ 31/1/3.short

2. Health Canada. National aboriginal youth suicide prevention strategy (NAYSPS), 2013. Available: http://www.hc-sc.gc.ca/fniah-spnia/ promotion/suicide/index-eng.php\%5Cnhttp://www.hc-sc.gc.ca/ fniah-spnia/promotion/suicide/index-fra.php

3. Tempier R. Suicide among aboriginals: a 'burning' public health issue in need of solutions. Can J Psychiatry 2016;61:682-683.

4. Truth and Reconcilliation Commission of Canada. Truth and reconciliation commission of Canada: calls to action, 2015. Available: http://www.usip.org/sites/default/files/file/resources/collections/ commissions/Peru01-Report/Reru01-Report Vol1Ch1-4.pdf

5. Bombay A, Matheson K, Anisman H. The impact of stressors on second generation Indian residential school survivors. Transcult Psychiatry 2011;48:367-91.

6. Health Council of Canada. The health status of Canada's first nations, Métis and Inuit peoples, 2005

7. Leenaars AA. Suicide among Indigenous peoples: introduction and call to action. Arch Suicide Res 2006;10:103-15.

8. Barrish HH, Saunders M, Wolf MM. Good behavior game: effects of individual contingencies for group consequences on disruptive behavior in a classroom. J Appl Behav Anal 1969;2:119-24.

9. Bradshaw CP, Zmuda JH, Kellam SG, et al. Longitudinal impact of two universal preventive interventions in first grade on educational outcomes in high school. J Educ Psychol 2009;101:926-37.

10. Kellam SG, Rebok GW, lalongo N, et al. The course and malleability of aggressive behavior from early first grade into middle school: results of a developmental epidemiologically-based preventive trial. $J$ Child Psychol Psychiatry 1994;35:259-81.

11. Petras H, Kellam SG, Brown CH, et al. Developmental epidemiological courses leading to antisocial personality disorder and violent and criminal behavior: effects by young adulthood of a universal preventive intervention in first- and second-grade classrooms. Drug Alcohol Depend 2008;95 (Suppl 1):S45-S59.
12. Dolan LJ, Kellam SG, Brown $\mathrm{CH}$, et al. The short-term impact of two classroom-based preventive interventions on aggressive and shy behaviors and poor achievement. J Appl Dev Psychol 1993;14:317-45.

13. Kellam SG, Brown CH, Poduska JM, et al. Effects of a universal classroom behavior management program in first and second grades on young adult behavioral, psychiatric, and social outcomes. Drug Alcohol Depend 2008;95 (Suppl 1)-S5-S28.

14. Poduska JM, Kellam SG, Wang W, et al. Impact of the good behavior game, a universal classroom-based behavior intervention, on young adult service use for problems with emotions, behavior, or drugs or alcohol. Drug Alcohol Depend 2008;95 (Suppl 1):S29-S44.

15. Katz C, Bolton SL, Katz LY, et al. A systematic review of school-based suicide prevention programs. Depress Anxiety 2013;30:1030-45.

16. Domitrovich CE, Pas ET, Bradshaw CP, et al. Individual and school organizational factors that influence implementation of the Pax good behavior game intervention. Prev Sci 2015;16:1064-74.

17. Becker KD, Bradshaw CP, Domitrovich C, et al. Coaching teachers to improve implementation of the good behavior game. Adm Policy Ment Health 2013;40:482-93.

18. Cunningham V, Irish National Teachers' Organsation. Irish teachers' journal 2013;1.

19. Nolan JD, Houlihan D, Wanzek M, et al. The good behavior game: a classroom-behavior intervention effective across cultures. Sch Psychol Int 2014;35:191-205.

20. Wilcox HC, Kellam SG, Brown CH, et al. The impact of two universal randomized first- and second-grade classroom interventions on young adult suicide ideation and attempts. Drug Alcohol Depend 2008;95 (Suppl 1):S60-S73.

21. Durlak JA, DuPre EP. Implementation matters: a review of research on the influence of implementation on program outcomes and the factors affecting implementation. Am J Community Psychol 2008:41:327-50.

22. Rabin BA, Brownson RCDeveloping the Terminology for Dissemination and Implementation Research. In: Brownson RC, Colditz GA, Proctor EK, eds. Dissemination and implementation research in health: translating science to practice. Oxford University Press, 2012.

23. National Institute of Health. Dissemination and implementation research in health (R01). Available: https://grants.nih.gov/grants/ guide/pa-files/par-16-238.html [Accessed 02 Aug 2018].

24. Proctor EK, Brownson RC. Measurement issues in dissemination and implementation research. In: Brownson RC, Colditz GA, Proctor EK, eds. Dissemination and implementation research in health: translating science to practice. Oxford Scholarship Online, 2012.

25. Dane AV, Schneider BH. Program integrity in primary and early secondary prevention: are implementation effects out of control? Clin Psychol Rev 1998;18:23-45.

26. O'Brien BC, Harris IB, Beckman TJ, et al. Standards for reporting qualitative research: a synthesis of recommendations. Acad Med 2014;89:1245-51.

27. Domitrovich CE, Bradshaw CP, Berg JK, et al. How do school-based prevention programs impact teachers? findings from a randomized trial of an integrated classroom management and Social-Emotional program. Prev Sci 2016;17:325-37.

28. Han SS, Weiss B. Sustainability of teacher implementation of school-based mental health programs. J Abnorm Child Psychol 2005;33:665-79.

29. Rohrbach LA, Graham JW, Hansen WB. Diffusion of a schoolbased substance abuse prevention program: predictors of program implementation. Prev Med 1993;22:237-60.

30. Wehby JH, Maggin DM, Moore Partin TC, et al. The impact of working alliance, social validity, and teacher burnout on implementation fidelity of the good behavior game. School Ment Health 2012;4:22-33.

31. Becker KD, Darney D, Domitrovich C, et al. Supporting universal prevention programs: a two-phased coaching model. Clin Child Fam Psychol Rev 2013;16:213-28.

32. Jiang D, Mayer T, Boyd L. Evaluation of Pax program in Manitoba: indigenous vs non-indigenous, 11th SCTC Annual Conference, Winnipeg, 2018. 